\title{
Cytotoxicity of three commercial orthodontic elastomeric ligature brands
}

\author{
Peerapong Tua-ngam ${ }^{1}$, Nittaya Jira-anankul ${ }^{2}$, Niwat Anuwongnukroh ${ }^{3}$, Surachai Dechkunakorn ${ }^{4}$ and Pasaree Laokijcharoen ${ }^{5}$ \\ ${ }^{1}$ Research Office, Faculty of Dentistry, Mahidol University, 6 Yothee Road, Rajthevee, Bangkok Thailand \\ ${ }^{2}$ Postgraduate student of specialty training program in Orthodontics, Faculty of Dentistry, Mahidol University, 6 Yothee Road, Rajthevee, Bangkok \\ Thailand \\ ${ }^{3}$ Department of Orthodontics, Faculty of Dentistry, Mahidol University, 6 Yothee Road, Rajthevee, Bangkok Thailand \\ ${ }^{4}$ Department of Orthodontics, Faculty of Dentistry, Mahidol University, 6 Yothee Road, Rajthevee, Bangkok Thailand \\ ${ }^{5}$ National Metal and Materials Technology Center, National Science and Technology Development Agency, Ministry of \\ Science and Technology
}

\begin{abstract}
Objective: This study aimed to evaluate cytotoxicity of three commercial brands of orthodontic elastomeric ligatures. Materials and Methods: The three commercial orthodontic elastomeric ligature brands were C-brand, T-brand and U-brand from different manufacturing countries. The cytotoxic assay was performed using cell cultures (L929) which were subjected to the cell viability test with methyl-tetrazolium (MTT). The L929 cell line was grown in 96-well tissue culture plates $\left(1 \times 10^{5}\right.$ cells $\left./ \mathrm{cm}^{3}\right)$. Elastomeric ligatures $(0.2 \mathrm{~g})$ from each brand was placed in $1 \mathrm{ml}$ of Minimum Essential Medium (MEM) at $37^{\circ} \mathrm{C}$ with $5 \% \mathrm{CO}_{2}$ at $100 \%$ humidity in an incubator for 24 hours. After incubation, the cell mitochondrial activity was evaluated by the MTT test for detecting viable cells from optical density according to ISO 10993-5: 2009 (E) test procedure. Cytotoxic effects were determined by the percentage of cell viability. Results: Microscopic investigation showed that all commercial elastomeric ligatures caused alterations in the fibroblast cell morphology from an elongated to a spherical form. The cell viability of C-brand, T-brand and U-brand were 51.10, 73.04 and 93.04\%, respectively. Conclusion: T-brand and U-brand orthodontic elastomeric ligatures were non cytotoxic potential. U-brand had the greatest cell viability and C-brand had the lowest cell viability at 24 hours.
\end{abstract}

\section{Introduction}

Elastomeric ligatures are commonly used nowadays in orthodontic treatment. They are used to engage the archwires to orthodontic brackets. The force exerted by an elastomeric ligature appears dependent upon the magnitude of the initial force, the duration that the force may be applied and the decay rate of the ligature. In addition to the initial extension force and residual forces, the size and dimension of elastomeric ligature also affect the force exerted on the archwire. Currently, orthodontists prefer to use elastomeric ligatures to stainless steel ligatures because the former can be easily used, patient-freindly in nature, esthetic appearance and less time is spent to engage archwires in the orthodontic brackets. Elastomeric ligatures are placed in direct contact with patient's soft tissues, often for months and years during the course of the orthodontic treatment. Moreover, elastomeric ligatures produced from polyurethane are cytotoxic to oral mucosal cells due to the presence of oligomers (low molecular weight polymers), unreacted monomers or other additives [1]. When a new product of elastomeric ligature is introduced in the orthodontic market, the manufacturer tends to promote the clinical performance but they are usually reluctant to inform about the composition, the manufacturing process, or the results of biocompatibility test. Therefore, it is necessary to determine the safety and biocompatibility of these products to prevent potential allergic or toxic reactions to the patients.

The toxicity test of dental products by using cell culture medium is a valid method to determine a material's biological behavior [2]. The suggested testing methods (ISO 10993; ISO 7405) use cell counting, dye-binding, metabolic impairment or membrane integrity as endpoints of the cytotoxicity test or assay. The ISO standard $10993-$ 5 requires the biological evaluation of medical devices. The manufacturer is responsible for ensuring that their products are safe to be used and the required tests should be performed. The direct use of cell and colony counting as an assay endpoint is commonly used but it is probably the least reliable method [3].

Dechkunakorn et al. (2012) and Anuwongnukroh et al. (2013) [3,4] compared three commercially available elastomeric ligatures of different colors in relation to their initial and residual forces and also compared the dimensions and residual forces of various orthodontic elastomeric ligatures. However, there has been lack of study in terms of the cytotoxicity of these elastomeric ligatures. Nowadays, new elastomeric ligatures continue to be marketed, rapid and sensitive tests for examining their toxic effect are needed for patient safety. The purpose of this in vitro study was to compare the 
cytotoxicity of three different commercial elastomeric ligatures: C-brand, T-brand and U-brand.

\section{Materials and methods}

The three different commercial brands of orthodontic elastomeric ligatures (Table1) were tested according to ISO 10993-5: 2009(E) test procedure.

Table 1. The three commercial orthodontic elastomeric ligatures

\begin{tabular}{|c|c|l|}
\hline Product & Manufacturer & Color \\
\hline C-brand & China & Blue \\
\hline T-brand & Thailand & Blue \\
\hline U-brand & USA & Blue \\
\hline
\end{tabular}

All three commercial elastomeric ligatures were compared to the positive control, polyurethane film containing $0.1 \%$ zinc diethyldithiocarbamate (ZDEC). Plastic coverslip Lot. No.600562, was used as a negative control.

\subsection{Cytotoxicity tests}

\subsubsection{Cell preparation (1st day)}

The L929 cell line (Lot Number: 2869501) was the target cell used in this experiment. The cells were fed with a Minimum Essential Medium (MEM) $100 \mu \mathrm{L}$, completed medium, in 96-well tissue culture plates at the concentration of $1 \times 10^{5}$ cells per well. Each well was maintained at $37^{\circ} \mathrm{C}$ with $5 \% \mathrm{CO}_{2}$ at $100 \%$ humidity in an incubator for 24 hours to obtain a monolayer cell growth. 1.2 Orthodontic elastomeric ligature preparation for specimen (2nd day)

Orthodontic elastomeric ligatures $(0.2 \mathrm{~g})$ from each manufacturer were sterilized by ultraviolet radiation for 40 minutes. Thereafter, $1 \mathrm{ml}$ of $10 \%$ MEM was used to cover these sterile orthodontic elastomeric ligatures. This was maintained at $37^{\circ} \mathrm{C}$ with $5 \% \mathrm{CO}_{2}$ at $100 \%$ humidity in an incubator for 24 hours to obtain a solution of orthodontic elastomeric ligature. Positive control with a coverage of $6 \mathrm{~cm}^{2} / \mathrm{ml}$ was prepared and negative control with a size of $6 \mathrm{~mm}$ was immersed in $1 \mathrm{ml}$ of $10 \%$ MEM. This was maintained at $37^{\circ} \mathrm{C}$ with $5 \% \mathrm{CO}_{2}$ at $100 \%$ humidity in an incubator for 24 hours.

1.3 MTT assay (3rd day)

All samples of the orthodontic elastomeric ligatures along with the positive and negative and reagent controls were removed from the well tissue culture plates. Each well was washed with phosphate-buffered saline (PBS). Freshly prepared $50 \mu \mathrm{L}$ of methyl tetrazolium (MTT) $(0.1 \%$ without supplements and without phenol red) solution was dispensed into each well and incubated for two hours. Then MTT solution was removed and washed with PBS. One hundred microliters of isopropanol was dispensed into each well. The plates were agitated on a shaker to enhance the dissolution of formazan for $30 \mathrm{~min}$ and the spectrophotometric absorbance was measured at $570 \mathrm{~nm}$ using isopropanol as the blank.

The data generated was recorded in the raw data file. The results were presented in tabular form including experimental groups with the test samples and positive and negative and reagent controls.

A decrease in the number of living cells results in a decrease in the metabolic activity in the sample. This decrease directly correlates to the amount of blue-violet formazan formed, as monitored by the optical density (OD) at $570 \mathrm{~nm}$. To calculate the reduction of cell viability compared to the blank, the following equation was used

$$
\text { Cell viability } \%=\frac{100 \times \text { OD }}{\mathrm{OD}_{570 \mathrm{~b}}} \underline{570 \mathrm{e}}
$$

OD570e represented the mean value of the measured OD of the $100 \%$ extracts of the test samples.

OD570b represented the mean value of the measured OD of the blanks.

\subsection{Evaluation of cell viability}

The lower the cell viability \% value, the higher was the cytotoxic potential of the test samples. If cell viability was reduced to $<70 \%$ of the blank, it was considered to have cytotoxic effects. If the $50 \%$ extract of the test samples had at least the same or higher cell viability than the $100 \%$ extract, the test was repeated.

\section{Results}

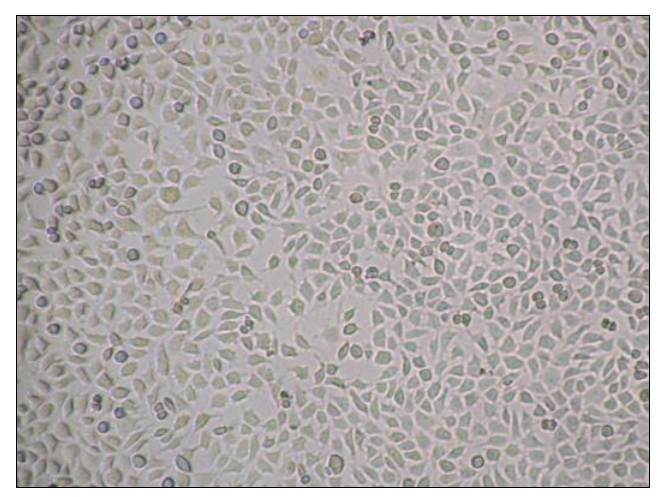

(a)

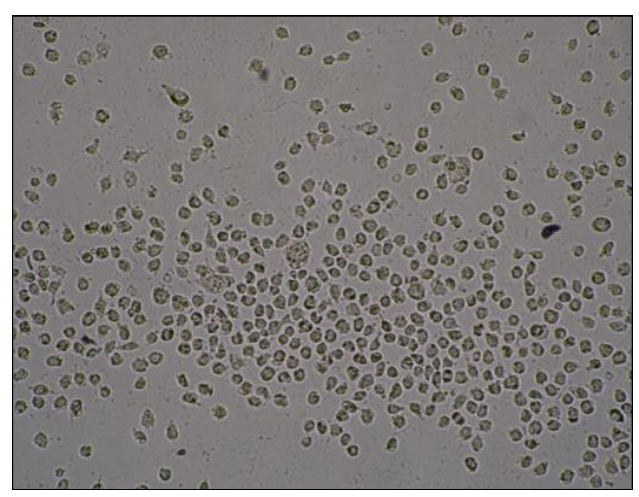

(b) 


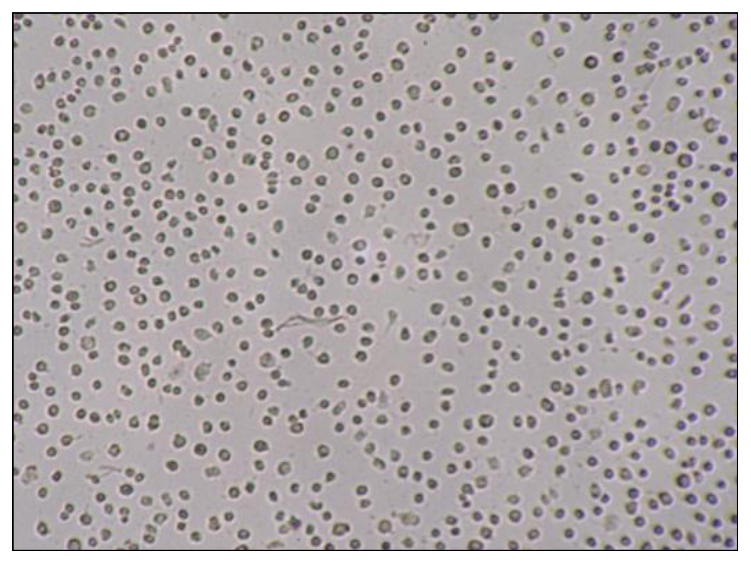

(c)

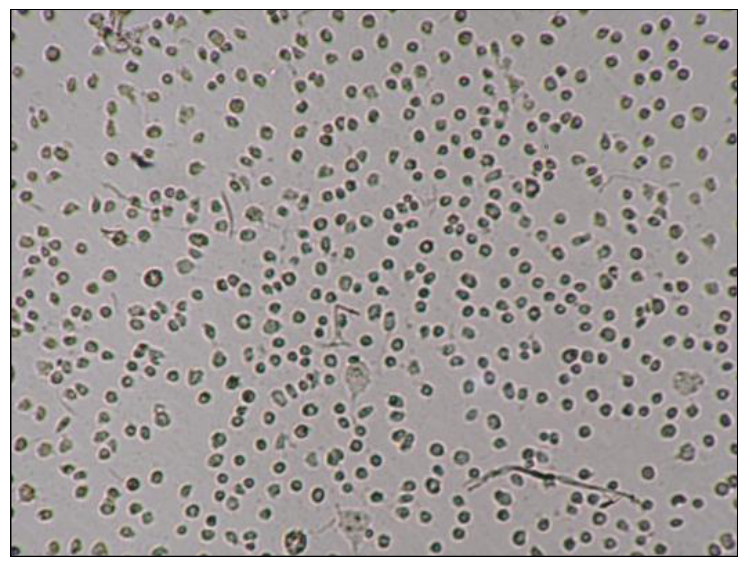

(d)

Figure 1. Microscopic investigation of morphological changes in L929 cells at day 3. (a) Control, (b) C-brand, (c) T-brand and (d) U-brand.

The cytopathic effect of elastomeric ligatures on the L929 cells at day 3 is shown in Figure 1. In the control group, the cells had typical multipolar fibroblast morphology. Cells had elongated shapes and were attached to the surface of microplate. However, C-brand, T-brand and U-brand elastomeric ligatures had altered cell morphology. A number of cells had lost their elongated shapes and had a spherical morphology.

Table 2. Descriptive result for cell viability of orthodontic elastomeric ligatures and control groups

\begin{tabular}{|c|c|c|c|}
\hline $\begin{array}{c}\text { Type of } \\
\text { orthodontic } \\
\text { elastomeric } \\
\text { ligature }\end{array}$ & $\begin{array}{c}\text { Positive } \\
\text { control } \\
\mathbf{( \% )}\end{array}$ & $\begin{array}{c}\text { Negative } \\
\text { control } \\
\mathbf{( \% )}\end{array}$ & $\begin{array}{c}\text { Cell } \\
\text { Viability } \\
(\mathbf{\%})\end{array}$ \\
\hline C-brand & 9.74 & 93.82 & 51.10 \\
\hline T-brand & 8.47 & 100.99 & 73.04 \\
\hline U-brand & 8.10 & 104.20 & 93.04 \\
\hline
\end{tabular}

The results showed the cell viability of C-brand, Tbrand and U-brand were 51.10, 73.04 and 93.04\%, respectively. C-brand had the lowest cell viability at 24 hours. The cell viability in the U-brand solution was
93.04\% which signified that it had the lowest toxicity among all the other samples.

\section{Discussion}

Elastomeric ligatures are mostly made of polyurethane. They are synthesized by extending a polyester or a polyether glycol or polyhydrocarbon diol with a diisocyanate [5]. The two main methods of processing the elastomeric ligatures are injection molding and die stamping. Injection molded ligatures are made by injection of liquefied elastomeric material into a mold and curing it. The die-stamped elastomers have been found to be more consistent in mechanical properties. In addition, the incorporation of the additives in the polymer can improve their mechanical properties; for instance, some company may incorporate fillers in the polymer matrix, in a similar manner to that for composite restorative resins in order to improve the strength of the elastomers [6].

Under clinical conditions, it is important that the elastomeric ligature provide sufficient force to maintain full engagement of the archwire within the bracket slot. Many researchers revealed a large force decay during the first 24 hours after placement of the elastomeric ligatures. Factors precipitating the rapid force decay are the oral environment, $\mathrm{pH}$, temperature variations in the oral environment, along with the accumulation of plaque and formation of microbial colonies on the surfaces of the elastomeric liagatures. These factors may affect the structure, surface properties, and the conformation of the polyurethanes. Moreover, water also acts as a plasticizer by weakening intermolecular forces in the polyurethanes, leading to chemical degradation [7]. These polymerization chemicals can pose some risk to patients.

This study chose L-929 cell mouse fibroblasts to represent primary human gingival fibroblasts suggested by ISO 10993-5: 2009(E) [8].

In this study, we used the monolayer [9] of cell culture model and used dye-uptake technique for determining cytotoxicity with spectrophotometry.

Spectrophotometric essay allows rapid and reliable evidence of cell viability to be obtained based on the use of vital stain incorporated by viable cells $[10,11]$. Dead or damaged cells cannot incorporate vital satin and are thus not recognized on optical reading.

As sterilization is a prerequisite for cytotoxicity essays, ultraviolet radiation [12,13] was performed on each elastic surface used in this study for 40 minutes. It was observed that all elastics exhibited the same color aspect and malleability after sterilization with the UV light.

Cell viability in the tested group (Table 2) showed a range of 51.10-93.40\% which indicated that U-brand and T-brand were non-cytotoxic (cytotoxicity scale $<70 \%$ ). Plastic coverslip, which was used as the negative control, did not produce any cytotoxic response when tested in accordance to ISO10993-5. On the other hand, the extracts from polyurethane film containing $0.1 \%$ zinc diethyldithiocarbamate (ZDEC), which was used as the 
positive control, showed cell viability of $8.10-9.74 \%$ signifying a cytotoxic response.

From the results of the study, it was shown that Ubrand had the greatest cell viability $(93.04 \%)$, whereas and $\mathrm{C}$-brand had the least cell viability $(51.10 \%)$. It was interesting to observe that all of the tested samples had non-cytotoxicity effects except C-brand. Furthermore, cell morphology of the L929 cells exposed with the solution of C-brand, T-brand and U-brand was also investigated and it was found that structure of the cells changed to a spherical form. This effect may have been related to the inhibition of cell growth after exposure of the cells to the elastomeric ligatures.

The composition and additives of the elastomeric ligatures as well as their manufacturing process may have a profound effect on the cytotoxicity [1]. Polyurethanes, which are the materials used for production of orthodontic elastomeric ligatures, can be dangerous due to the presence of oligomers (polymers of low molecular weight and bearing a short chain) or un-polymerized chains. These are formed during the manufacturing process and can later readily dissolve in the oral cavity [14]. The cell viability of C-brand, T-brand and U-brand were 51.10, 73.04 and $93.04 \%$, respectively. The differences in cell viability may be due to the differences in manufacturing process. Furthermore, the composition of the elastomeric ligatures along with the additives could also play a major role in its cytotoxicity when compared to their manufacturing process. However, further investigations are necessary to validate this effect.

Another concern for cytotoxicity is the effects of polymer biodegradation [15]. Through exposure to light, air, warm temperatures and moisture, polymers suffer mechanical and chemical transformations. The effect of enzymes on polymers are variable and may differ among the products [16]. The accumulation of plaque [17] comprising both aerobic and anaerobic microbes may also degrade the polymers.

As these orthodontic ligatures are commonly used in orthodontics, emphasis should be given regarding their safety and biocompatibility, as they come in close contact with oral tissues. In patients with gingival hyperplasia and potential periodontal problems, the elastomeric ligatures with the lowest cytotoxicity or preferably metal ligatures should be used [18].

\section{Conclusion}

1) All orthodontic elastomeric ligatures in this study were non-cytotoxic potential except C-brand.

2) Among the tested elastomeric ligatures, U-brand showed the greatest cell viability in the time interval of 24 hours.

3) The cell viability of C-brand was lower than the other samples.

\section{References}

1. Thomas M Graber, Theodore Eliades, Athanasiou AE. Risk management in orthodontics. 1 ed. United States: Quintessence Publishing Co, Inc; (2004)
2. Schmalz G. J Dent. 22:S6-11. (1994)

3. Dechkunakorn S, Viriyakosol N, Anuwongnukroh N, Suddhasthira T, Laokijcharoen P, Churnjitapirom P, et al. Advanced Materials Research. 674-80. (2012)

4. Anuwongnukroh N, Jiraanankul N, Dechkunakorn S, Churnjitapirom P, Tua-ngam P. Advanced Materials Research. 315-20. (2013)

5. Wong AK. Angle Orthod. 46 :196-205.(1976)

6. Brantley WA, Eliades T. Orthodontic materials :scientific and clinical aspects 2001, Thieme Stuttgart, New York

7. Huget FH, Reynolds WG. Am J Orthod. 67 :554-62. (1975)

8. Schedle A, Samorapoompichit P, Rausch-Fan XH, Franz A, Fureder W, Sperr WR, et al. J Dent Res. 74(8):1513-20. (1995)

9. Tomakidi P, Koke U, Kern R, Erdinger L, Kruger H, Kohl A, et al. J Orofac Orthop. 61(1):2-19. (2000)

10. Pithon MM, dos Santos RL, Martins FO, Romanos MT, Araujo MT. Aust Orthod J. 26(1):16-20. (2010)

11. Rogério Lacerda Dos Santos, Matheus Melo Pithon, Márlio Vinícius de Oliveira, Gabriella da Silva Mendes, Maria Teresa Villela Romanos, Ruellas ACdO. Journal Oral Sciences. 7(24):1520-6. (2008)

12. Rogério Lacerda dos SANTOS, Matheus Melo PITHON, Gabriella da Silva MENDES, Maria Teresa Villela ROMANOS, RUELLAS4 ACdO. J Appl Oral Sci. 17(4):326-9. (2009)

13. Dos Santos RL, Pithon MM, Martins FO, Romanos MT, de Oliveira Ruellas AC. Orthod Craniofac Res. 13(1):28-33. (2010)

14. Toxicity and safe handling of diisocyanates and ancillary chemicals. A code of practice for polyurethane flexible foam and elastomer manufacture. (2000)

15. Huget EF, Patrick KS, Nunez LJ. J Dent Res. 69(2):496-501. (1990)

16. Santerre JP, Shajii L, Tsang H. J Dent Res. 78(8):1459-68. (1999)

17. Sukontapatipark W, el-Agroudi MA, Selliseth NJ, Thunold K, Selvig KA. Eur J Orthod. 23(5):475-84. (2001)

18. Lacerda Dos Santos R, Pithon MM, Romanos MT. Angle Orthod. 82(4):709-14. (2012) 